\title{
Geometry of the hemispherical radiometric footprint over plant canopies
}

\author{
B. Marcolla ${ }^{1}$ A. Cescatti ${ }^{2}$ (D)
}

Received: 3 August 2016 / Accepted: 8 November 2017 /Published online: 18 November 2017

(C) The Author(s) 2017. This article is an open access publication

\begin{abstract}
Radiometric measurements of hemispherical surface reflectance and long-wave irradiance are required to quantify the broadband albedo and the outgoing thermal radiation. These observations are typically integrated with eddy covariance measurements of sensible and latent heat fluxes to characterize the surface energy budget. While the aerodynamic footprint has been widely investigated, the geometry of the hemispherical radiometric footprint over plant canopies has been rarely tackled. In the present work, the size and shape of the hemispherical radiometric footprint are formalized for a bare surface and in presence of a vegetation cover. For this purpose, four idealized canopies are analyzed and the dependency of the radiometric footprint on leaf area index and canopy height is explored. Besides, the radiometric footprint is compared with the aerodynamic footprint in conditions of neutral stability. It was observed that almost $100 \%$ of the hemispherical radiometric signal originates within a distance of a few radiometer heights, while only about $50-80 \%$ of the cumulative aerodynamic signal is generated within a distance of about 20 sensor heights. In order to achieve comparable extensions of the footprint areas, hemispherical radiometric measurements should therefore be taken about 6-15 times higher than turbulent flux ones, depending on the vegetation type. The analysis also highlights that the size of the radiative footprint decreases at increasing leaf area index, whereas the
\end{abstract}

A. Cescatti

alessandro.cescatti@jrc.ec.europa.eu

1 IASMA Research and Innovation Centre, Sustainable Agro-Ecosystems and Bioresources Department, Fondazione Edmund Mach, San Michele all'Adige, TN, Italy

2 European Commission, Joint Research Centre, Directorate for Sustainable Resources Ispra, Via Enrico Fermi, 2749, I-21027 Ispra, VA, Italy aerodynamic footprint shows an opposite behavior. For the abovementioned reasons, this work may support the interpretation of energy flux measurements and the optimal design of eddy covariance stations located in heterogeneous sites.

\section{Introduction}

Radiometric measurements of broadband upwelling shortwave and long-wave radiation are fundamental in micrometeorology to quantify surface albedo, net radiation and the surface energy balance (Law et al. 2002; Eklundh et al. 2011; Cescatti et al. 2012; Stoy et al. 2013). In addition, in situ observations of spectral reflectance are increasingly applied to link surface measurements of energy and carbon fluxes with Earth observations (Gamon et al. 2006). The measurements of hyper-spectral surface reflectance at eddy covariance sites is an important step for the spatial extrapolation of in situ measurements with remote sensing retrievals from satellite platforms (Balzarolo et al. 2011) and to parameterize light use efficiency models for the up-scaling of gross primary productivity (GPP) (Sims et al. 2006; Meroni et al. 2009; Meroni et al. 2011; Peñuelas et al. 2011; Rossini et al. 2012).

To fulfill the objectives listed above, radiometric measurements have to be integrated with observations of surface fluxes performed with the eddy covariance technique. This methodology is nowadays applied for the quantification of the turbulent exchange of carbon, water and energy between vegetation and the atmosphere at hundreds of experimental sites organized in continental networks (Baldocchi 2003). Given the typical inhomogeneity of the land surface in topography, soil properties and vegetation cover, an evaluation of the spatial footprint of the observations is required for the proper integration of hemispherical radiometric measurements with turbulent fluxes. In fact, all components in a 
measurement system should be well matched to each other in order to make their retrievals consistent and usable in a common contest (Schmid 1997).

The source area of eddy covariance measurements has been largely investigated with both modeling and experimental approaches in order to characterize the dependence of the footprint size on measurement height, canopy structure and atmospheric conditions (Markkanen et al. 2003; Rannik et al. 2003; Vesala et al. 2004; Marcolla and Cescatti 2005). On the contrary, the spatial footprint of hemispherical radiometric measurements over vegetated surfaces has not yet been formalized nor geometrically described. The quantitative description of the hemispherical radiometric footprint and its comparison with the aerodynamic footprint are ultimately required for the correct interpretation of flux measurements and for optimizing the setup of eddy covariance stations located in spatially heterogeneous landscapes. In fact, considering that the sources of both turbulent and radiative fluxes are often spatially inhomogeneous, the inability to match the source areas of turbulent fluxes with that of the upwelling radiative fluxes introduces a random error in the energy balance closure at flux sites (Wilson et al. 2002). As far as carbon fluxes are concerned, the mismatch of radiometric and turbulent fluxes may lead to uncertainties and biases in the parameterization of models for the prediction of GPP based on spectral indexes.

The objective of the present work is to provide a formal description of the hemispherical radiometric footprint over a vegetation cover. As example, four idealized plant types are investigated to show the dependence of the radiometric footprint on major structural properties of the canopy, like leaf area index (LAI) and canopy height. Finally, the hemispherical radiometric footprint of the idealized cases is compared with the aerodynamic footprint, in order to highlight their differences in size, shape and dependence on vegetation properties.

The formalization of the radiative footprint over plant canopies is currently lacking in the literature, whereas a considerable number of articles have focused on the formalization of the footprint of turbulent fluxes. The quantitative description of the radiative footprint is a prerequisite to perform a proper comparison with the turbulent footprint and, therefore, to detect the occurrence of footprint mismatch and to elaborate alternative solutions, either to avoid the problem (e.g. with a proper choice of measurement sites) or to face it with alternative technical solutions.

\section{Materials and methods}

\subsection{Radiometric footprint on bare soil}

According to Lambert's cosine law of radiation, the radiation flux $\left(F_{\mathrm{R}}\right)$ on an inverted flat plate radiometer received from a solid angle $\mathrm{d} \omega$ can be expressed as (Schwerdtfeger 1976; Schmid 1997):

$\mathrm{d} F_{\mathrm{R}}=I_{\mathrm{o}} \cos \theta d \omega$

where $I_{\mathrm{O}}$ is the normal component of the specific radiation intensity originated from a differential source area $\mathrm{d} A$ and $\mathrm{d} \omega$ is the differential solid angle from which $\mathrm{d} A$ is seen from the center of the radiometer plate.

Considering that the radiation flux originated from a solid angle $\mathrm{d} \omega$ on a sensor with hemispherical field of view is independent of the azimuthal angle $\varphi$ between the sensor and the area for the specific design of the sensor itself, it is convenient to integrate the radiance over concentric annulus centered at the sensor location (Fig. 1) and to express the signal as a mere function of the nadir angle $\theta$.

For this purpose, the solid angle $\mathrm{d} \omega$ subtended by a differential annulus of radial thickness $\mathrm{d} \theta$ at a nadir angle $\theta$ can be calculated as:

$\mathrm{d} \omega=2 \pi \sin \theta d \theta$.

Assuming that the observed surface is homogeneous and Lambertian (i.e. $I_{\mathrm{o}}$ is independent of $(\theta, \varphi)$ ), it is possible to model the contribution to the total signal of the radiance coming from a differential annulus by combining Eqs. (1) and (2) (Schwerdtfeger 1976; Meroni et al. 2011):

$\mathrm{d} F_{\mathrm{R}}=2 \pi I_{o} \sin \theta \cos \theta d \theta$

where $\cos \theta$ represents the $\operatorname{cosine}$ correction of the radiation intensity due to the vertical angle between the radiometer plate and the source, and $\sin \theta$ accounts for the area of the differential annulus at varying nadir angles (Fig. 2a).

It follows that the total flux from the entire hemisphere can be obtained integrating Eq. (3) from 0 to $\pi / 2$ obtaining $F_{R, t o t}=\pi I_{\mathrm{o}}$; hence, the total integrated footprint function for radiation is:

$\varphi_{R, t o t}=\frac{F_{R, t o t}}{I_{\mathrm{o}}}=\frac{I_{\mathrm{o}} \int_{0}^{\frac{\pi}{2}} 2 \pi \sin \theta \cos \theta d \theta}{I_{\mathrm{o}}}=\pi$,

while the normalized cumulative footprint function $F$ for a given $\theta$ can be expressed as (Fig. 2c):

$F(\theta)=\frac{\varphi_{R, \theta}}{\varphi_{R, t o t}}=\frac{\int_{0}^{\theta} 2 \pi \sin \theta \cos \theta d \theta}{\pi}=\sin ^{2} \theta$.

Given that $\theta=\tan ^{-1} \frac{x}{h_{\mathrm{s}}}$, where $x$ is the radial distance and $h_{\mathrm{s}}$ is the sensor height (Fig. 1), the cumulative footprint function can be expressed in terms of radial distance $x$ as follows (Fig. 2d):

$F(x)=\sin ^{2}\left(\tan ^{-1} \frac{x}{h_{\mathrm{s}}}\right)=\frac{x^{2}}{x^{2}+h_{\mathrm{s}}^{2}}$, 


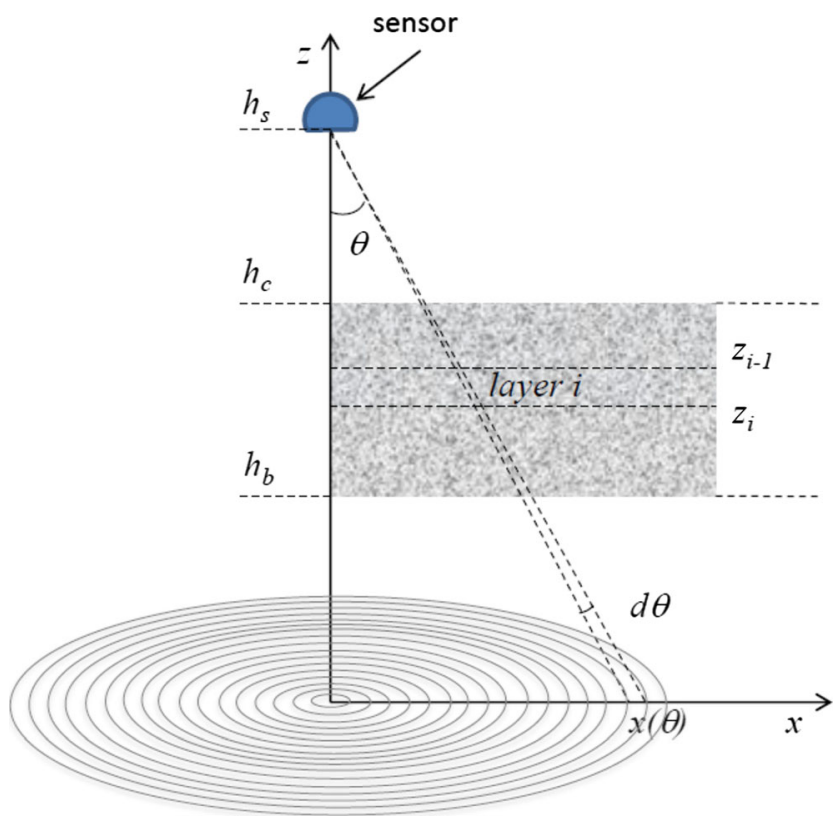

Fig. 1 Geometrical scheme of the observation system for hemispherical radiometric measurements of upwelling radiation with an inverted flat plate radiometer installed above a plant canopy; symbols are defined in the text

whereas its derivative with respect to $x$ is equal to (Fig. 2d):

$f(x)=\frac{2 x h_{\mathrm{s}}^{2}}{\left(x^{2}+h_{\mathrm{s}}^{2}\right)^{2}}$

Equation (7) is therefore the analytic formulation of the hemispherical radiometric contribution to a radiative flux measurement from a differential annulus over a flat surface as a function of the radial distance and can be expressed in terms of the nadir angle $\theta$ as (Fig. 2c):

$f(\theta)=2 \sin \theta \cos \theta$.

The proposed formalization focuses on hemispherical radiometric sensors for their importance in the measurement of surface energy fluxes (e.g. short-wave and long-wave upwelling radiation, net radiation, albedo). However, this analytical framework can be adapted to any narrower fore-optics by changing the integration domain.

\subsection{Radiometric footprint over plant canopies}

If a porous media, like a vegetation cover, is interposed between the sensor and the ground, the radiometric signal includes the contribution of both the canopy and the underlying soil in proportions determined by the structural characteristics and density of the vegetation layer.

Assuming a homogeneous distribution of phytoelements in the canopy space, the contributions to the radiometric signal $\left(f_{l \_}\right)$of a horizontal layer of leaves $\left(l_{-} i\right)$ at height $z$ and of the soil $\left(f_{s}\right)$ can be quantified by combining Eq. (8) with the probability of light interception by plants and soil as derived from a Markov light interception model (Nilson 1971). For this purpose, the canopy is discretized in $n$ horizontal layers. The soil contribution accounts for the probability of the light reflected (or thermal radiation emitted) by the soil to reach the inverted flat plate radiometer, which is the complement to one of the canopy interception.

The interception probability at height $z_{\mathrm{i}}$ can be formulated as:

$P\left(z_{i}\right)=1-\exp \left(-\frac{G(\theta) \Omega L A I\left(z_{i}\right)}{\cos (\theta)}\right)$,

where LAI is the leaf area index, cumulated from the canopy top down to the height $z_{\mathrm{i}}$ within the canopy, $G$ is the leaf angular distribution and $\Omega$ is the clumping coefficient (Nilson 1971). In the present analysis, we assumed a spherical distribution of the leaf angles, and therefore, $G$ was set constant and equal to 0.5 , whereas the leaf area was uniformly distributed along the vertical profile, and therefore, the cumulated LAI increases linearly between the canopy top and the canopy bottom. The values used for $\Omega$ are reported in Table 1 .

The interception probability in the $i$-th layer is equal to:

$P \_l_{\mathrm{i}}=P\left(z_{\mathrm{i}}\right)-P\left(z_{\mathrm{i}-1}\right)$,

and the contribution of an horizontal annulus in the $i$-th canopy layer to the total source area expressed as a function of $\theta$ is:

$f_{-} l_{i}(\theta)=2 \sin \theta \cos \theta P_{-} l_{i}$,

where $\theta=\tan ^{-1} \frac{x}{h_{\mathrm{s}}-z_{\mathrm{i}}}$ and $z_{\mathrm{i}} \in\left[h_{\mathrm{b}}, h_{\mathrm{c}}\right]$, being $h_{\mathrm{b}}$ and $h_{\mathrm{c}}$ the canopy bottom and top heights, respectively.

Since the same $\theta$ corresponds to different horizontal distances $x$ at different heights, in order to compute the annular footprint functions at the same radial distances in every canopy layer, Eq. (11) was interpolated using the R function approx (https://www.r-project.org/) with the linear method and recalculated at fixed $x$ distances. The total canopy contribution was eventually calculated summing up all layer contributions at each distance:

$f_{\mathrm{c}}(x)=\sum_{\mathrm{i}} f_{-} l_{\mathrm{i}}(x)$

Since the total canopy interception is:

$P\left(h_{\mathrm{b}}\right)=1-\exp \left(-\frac{G \Omega L A I_{T O T}}{\cos \theta}\right)$,

where $L A I_{T O T}$ is the total canopy LAI, the contribution of a the concentric annulus of the soil surface to the radiometric source area can be calculated as follows: 


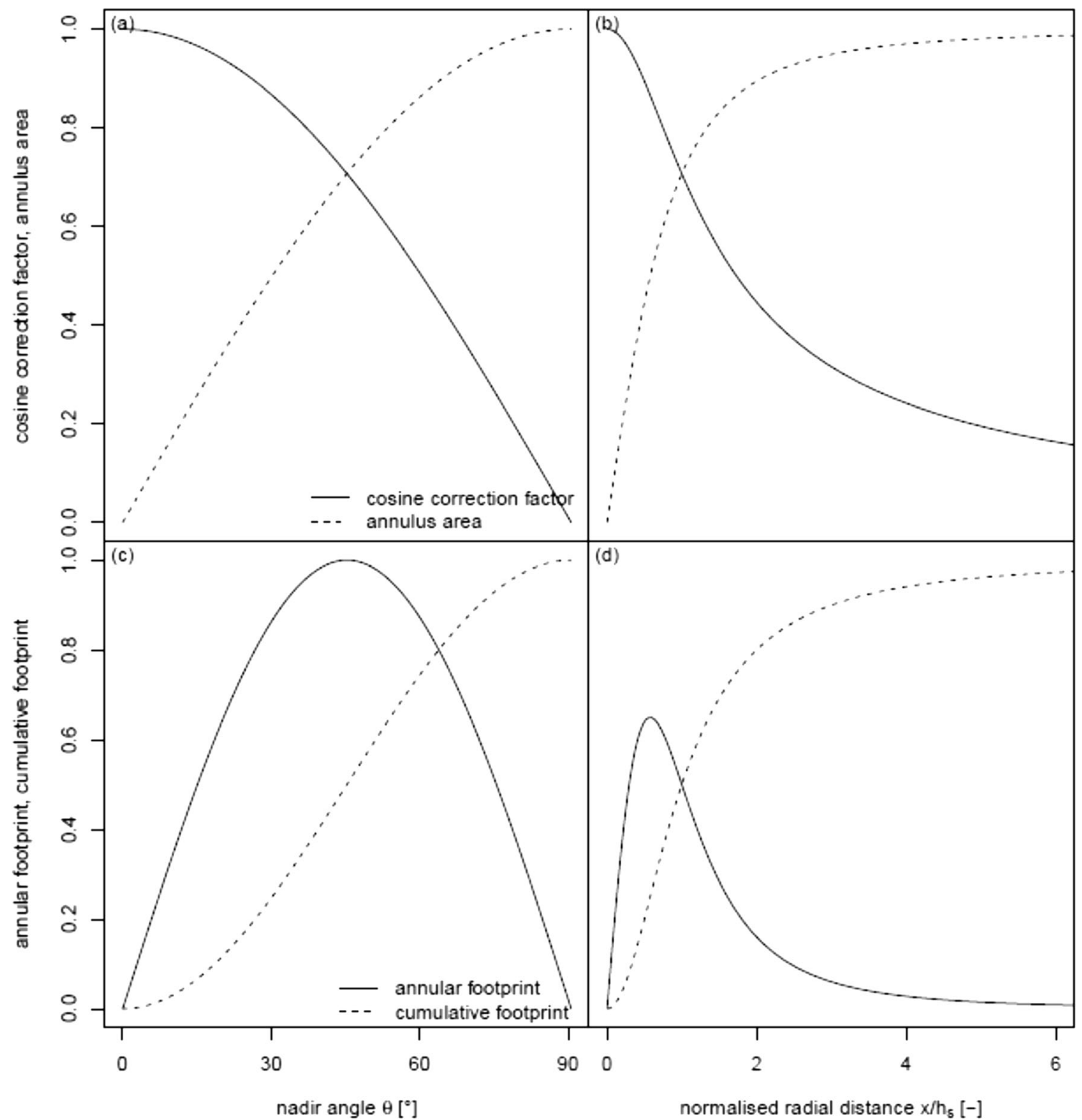

Fig. 2 Cosine correction factor and area of the annulus as a function of the nadir angle $\theta$ (a) and of the normalized radial distance $x / h_{\mathrm{s}}$ (b). Radiative annular footprint function (solid line) and cumulative footprint

(dashed line) above a bare surface as a function of the (c) nadir angle and of the (d) radial distance

$f_{\mathrm{s}}(x)$ was rescaled in order that its numerical integral over $x$ $f_{\mathrm{s}}(x)=2 \sin \theta \cos \theta \exp \left(-\frac{G \Omega L A I_{T O T}}{\cos \theta}\right)$,

where $\theta=\tan ^{-1} \frac{x}{h_{s}}$. equals the integral of $f_{\mathrm{s}}(\theta)$ over $\theta$ in $[0, \pi / 2]$, while $f_{\mathrm{c}}(x)$ was rescaled in order that its integral over $x$ equals the integral of 1 $-f_{\mathrm{s}}(\theta)$ over $\theta$ in $[0, \pi / 2]$.

Table 1 Structural parameters of the idealized plant canopies used in the analysis

\begin{tabular}{lllllll}
\hline Plant functional type & Acronym & Canopy top $(\mathrm{m})$ & Canopy base $(\mathrm{m})$ & Sensor height $(\mathrm{m})$ & LAI $\left(\mathrm{m}^{2} \mathrm{~m}^{-2}\right)$ & Clumping $\Omega(-)$ \\
\hline Cropland & CRO & 2 & 0.5 & 8 & 4 & 1 \\
Grassland & GRA & 0.5 & 0 & 6 & 5.5 & 0.9 \\
Evergreen needleleaf forest & ENF & 18 & 6 & 26 & 6 & 0.6 \\
Deciduous broadleaf forests & DBF & 22 & 14 & 30 & 5 & 0.9 \\
\hline
\end{tabular}


Finally, the total annular footprint function is calculated summing Eqs. (12) and (14) after rescaling:

$f_{\mathrm{t}}(x)=f_{\mathrm{c}}(x)+f_{\mathrm{s}}(x)$

For the sake of simplicity, the formulation presented in Eq. (9) is based on a 1D turbid medium analogy (Nilson 1971) and assumes that leaves are optically black, therefore ignoring the radiation scattered by vegetation. These assumptions allow the analytical formalization of the problem. In addition, the idealized 1D canopy structure is consistent with the assumptions made in the Lagrangian turbulent footprint model used in the present work. However, the numerical solution of the equation could make use of more complex radiative transfer models that account for horizontal heterogeneity in the canopy and leaf scattering (e.g. 3D turbid medium or ray tracing models; Cescatti and Niinemets 2005) to calculate the probability of light interception in canopy layers $\left(P l_{\mathrm{i}}\right.$, Eqs. (10) and (11)).

In the present analysis, four idealized plant canopies were used to explore the geometry of the radiometric footprint for different architectures, as described by the structural parameters reported in Table 1. In addition, for one short canopy (grassland, GRA) and for one tall canopy (deciduous broadleaf forest, $\mathrm{DBF}$ ), the radiometric footprint was calculated for variable LAI in the range 1-6 and for variable canopy height in the range $0.05-0.2 h_{\mathrm{s}}$ for GRA and $0.5-0.85 h_{\mathrm{s}}$ for DBF. The positions of the 50th and 80th percentiles were calculated for every pair of parameters (LAI, canopy height).

\subsection{Footprint of turbulent fluxes}

For the idealized canopies described in Table 1, the footprint of turbulent fluxes was estimated for neutral condition with the Lagrangian stochastic trajectory model proposed by Thomson (1987). For this purpose, the emitted tracer was simulated as the release of a large number of passive particles, which were assumed to follow perfectly the flow. The diffusion of the scalar was described by a stochastic differential equation (a generalized Langevin equation) which determines the motion of a Lagrangian particle in space and time (Thomson 1987; Kurbanmuradov et al. 2001; Markkanen et al. 2003; Rödenbeck et al. 2003; Kljun et al. 2004; Hsieh and Katul 2009).

The analytical second-order closure model of Massman and Weil (1999) was used to predict the vertical profile of mean wind speed, second moments and the dissipation rate of turbulent kinetic energy, accounting for the structural properties of the canopy as described by Marcolla et al. (2003). The model gives an analytical expression for the second-order moments as functions of the cumulative leaf drag area, coupling the exponential wind profile after Albini (1981) with the equations for the variances of the wind components reported in Wilson and Shaw (1977), under the assumptions of horizontal homogeneity of the canopy, steady-state condition for the wind field and neutrality. Particles were released at the $h=$ 0 to obtain the soil footprint function or uniformly released in the canopy layers to obtain the canopy footprint function.

Radiometric and flux footprint functions, calculated separately for canopy and soil fluxes, were finally compared for two of the idealized canopies (DBF and GRA) and in particular the positions of the 50th and of the 80th percentiles were calculated for LAI values ranging from 1 to $6 \mathrm{~m}^{2} \mathrm{~m}^{-2}$.

\section{Results and discussion}

\subsection{Radiometric footprint}

The theoretical case of the hemispherical radiometric footprint over a flat bare soil is presented in Fig. 2 as a function of the zenith angle $(\mathrm{a}, \mathrm{c})$, and of the radial distance $(\mathrm{b}, \mathrm{d})$. The figure shows that $50 \%$ of the total signal comes from a cone limited by a zenith angle of $45^{\circ}$ which corresponds to a horizontal distance $x=h_{\mathrm{s}}$ (Meroni et al. 2011), and $80 \%$ of the radiometric signal originates within a distance of about $2 h_{\mathrm{S}}\left(\theta \sim 63.4^{\circ}\right)$. The maximum contribution to the measured signal comes from the annulus located at a zenith angle of $45^{\circ}$.

When a vegetation layer is located between the sensor and the soil, the shape and size of the radiometric footprint change considerably. In Fig. 3, the contribution to the total source area by canopy layer annuli at increasing distance from the sensor is presented for the idealized ENF canopy, both as a function of the zenith angle and of the radial distance. The image clearly shows that the higher canopy layers have a larger impact on the radiometric footprint, while the position of the peak and $80 \%$ percentiles are rather similar between layers.

The radiometric annular footprint was then compared with the $1 \mathrm{D}$ aerodynamic footprint in neutral conditions in order to investigate the mismatch between the two (Fig. 4). The analysis was performed for the four model canopies described in Table 1. For all the canopies, the maximum contribution to the measured signal comes from a distance that is less than one radiometer height, and this distance is lower for high canopies if compared to short ones ( 0.25 and $0.5 h_{\mathrm{s}}$, respectively), while in the case of the turbulent flux footprint, the order of magnitude is of few sensor heights $\left(2 h_{\mathrm{s}}\right.$ for the two tall canopies, and 5 and $10 h_{\mathrm{s}}$ for the idealized cropland and grassland, respectively). The mismatch between the two footprints is more evident for short canopies, whereas both the aerodynamic and radiometric footprints are more leptokurtic for tall canopies.

As far as the cumulative footprint is concerned, while $100 \%$ of the signal recorded by a radiometer comes from a distance within few sensor heights, at a distance of $20 h_{\mathrm{s}}$, the aerodynamic signal reaches a percentage of $70 \%$ for CRO, 


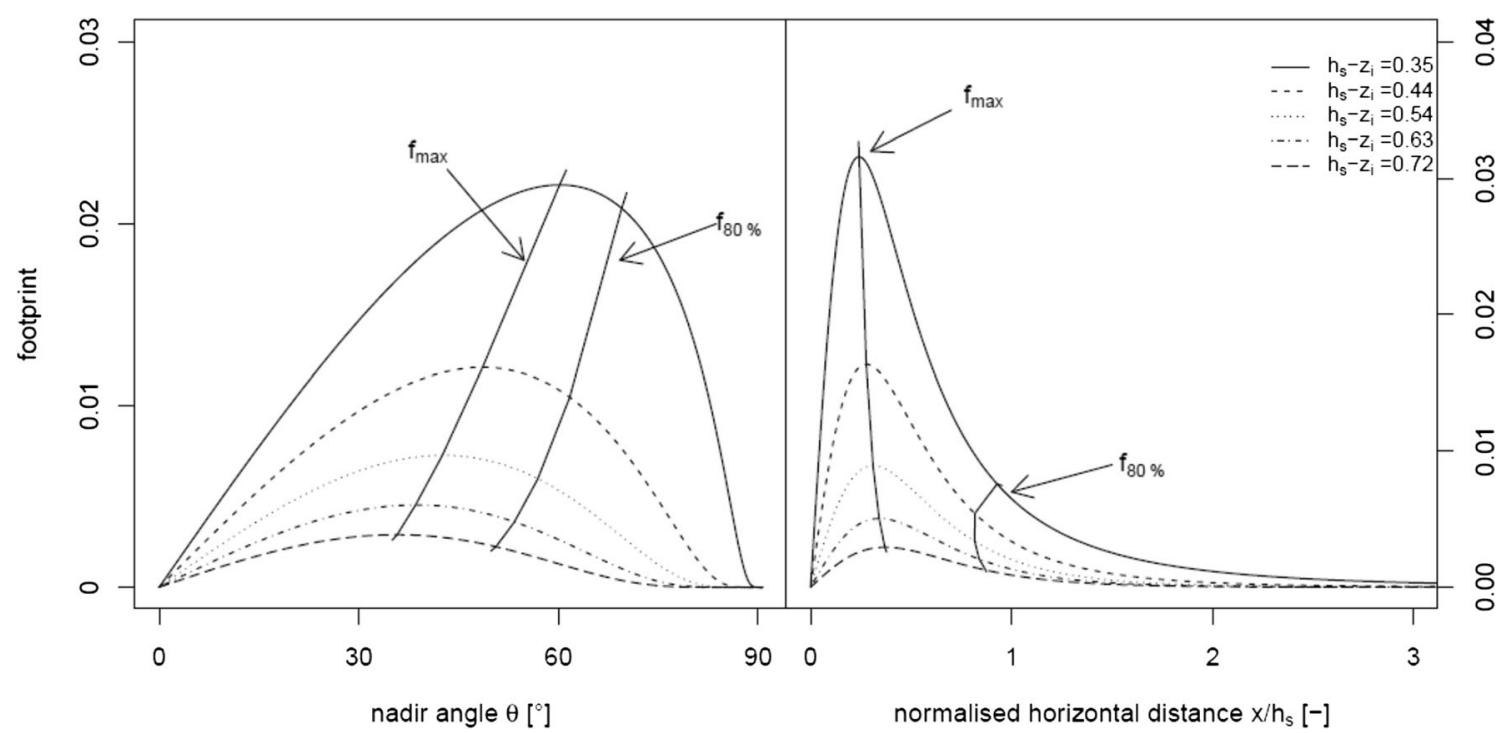

Fig. 3 Radiative annular footprint functions for different canopy layers as a function of the nadir angle and of the radial distance normalized with canopy height. Results are reported for increasing distance between the

$50 \%$ for GRA, and $88 \%$ for ENF and DBF. In addition to the size, also the shape is rather different between the aerodynamic and the radiative footprints. In fact, the footprint of turbulent fluxes is elongated in the wind direction, and therefore the cumulative footprint depends on the wind rose (Kljun et al. 2015). On the contrary, the radiative footprint in case of flat terrain is azimuthally symmetric relative to the vertical axis passing by the radiometer, whereas it becomes elliptical on slopes.

The mismatch of source areas of radiometric and aerodynamic flux measurements becomes important if the surface underlying the instruments is spatially heterogeneous, and when measurements coming from instruments characterized by different footprint are combined (e.g. in the calculation of the energy balance). This heterogeneity has been recognized as one of the potential causes of the lack of energy balance closure observed at most eddy covariance sites (Wilson et al. 2002; Stoy et al. 2013). Schmid (1997) reports a detailed discussion of the issues involved in matching scales of observations, in particular the different geometry and temporal dynamics of the source areas for radiometers and turbulent flux footprints. From the present analysis, in conditions of neutral stability, it turns out that the radiometer should be installed about 15 and 9 times higher than the eddy covariance system for GRA and CRO and about 6 times higher for ENF and DBF in order to match the distance of the radiometric and aerodynamic footprint at $80 \%$ of the total signal. Of course the problem of the temporal dynamics and directionality of turbulent flux footprint would still persist. If the wind has a dominant direction and therefore the turbulent footprint is not symmetric with respect to the tower location, an alternative method to maximize the overlap would be to center the radiometer with sensor $\left(h_{\mathrm{s}}\right)$ and the canopy layer $\left(z_{\mathrm{i}}\right)$. The positions of the peak and of the 80th percentile are also reported

respect to the turbulent footprint instead of locating it on the flux tower. Alternatively, the use of multiple radiometer sensors distributed in the turbulent footprint could be envisaged.

For the radiometric footprint, the dependence of the 50th and 80th percentiles on canopy height and LAI has been investigated, and the results are reported in Fig. 5 for a short canopy (GRA) and a tall canopy (DBF). For both vegetation types, the footprint size decreases at increasing LAI and at increasing canopy height. As expected, the distances are slightly higher for the short canopy if compared to the tall one.

Figure 6 reports the trend of the horizontal distance of the 50th and 80th percentiles of the radiometric (Eqs. (12) and (14)) and aerodynamic footprints as a function of LAI for GRA and DBF vegetation canopies; soil and canopy footprints are reported separately. For DBF, both the aerodynamic and the radiometric soil footprint are larger than those of the canopy. The size of the radiometric footprint shows a monotonic decreasing trend with LAI, whereas for the aerodynamic footprint, the distance of both the 50th and 80th percentiles peaks at intermediate values of LAI and then decreases. For the short canopy, given the proximity of vegetation layers to the ground, soil and canopy aerodynamic footprints are almost undistinguishable and increase with LAI. On the contrary, the size of the radiometric footprint for soil is smaller than that for the canopy and shows a monotonic decreasing trend. Hence, at increasing LAI, one should expect an increasing source area for the turbulent fluxes and a decreasing source area for radiometric measurements, which means an increasing spatial mismatch between the two set of observations. The complex interplay between LAI and aerodynamic footprint depends on several factors such as the impact of LAI on roughness length, and on the distance between the sources and the sensors. The 


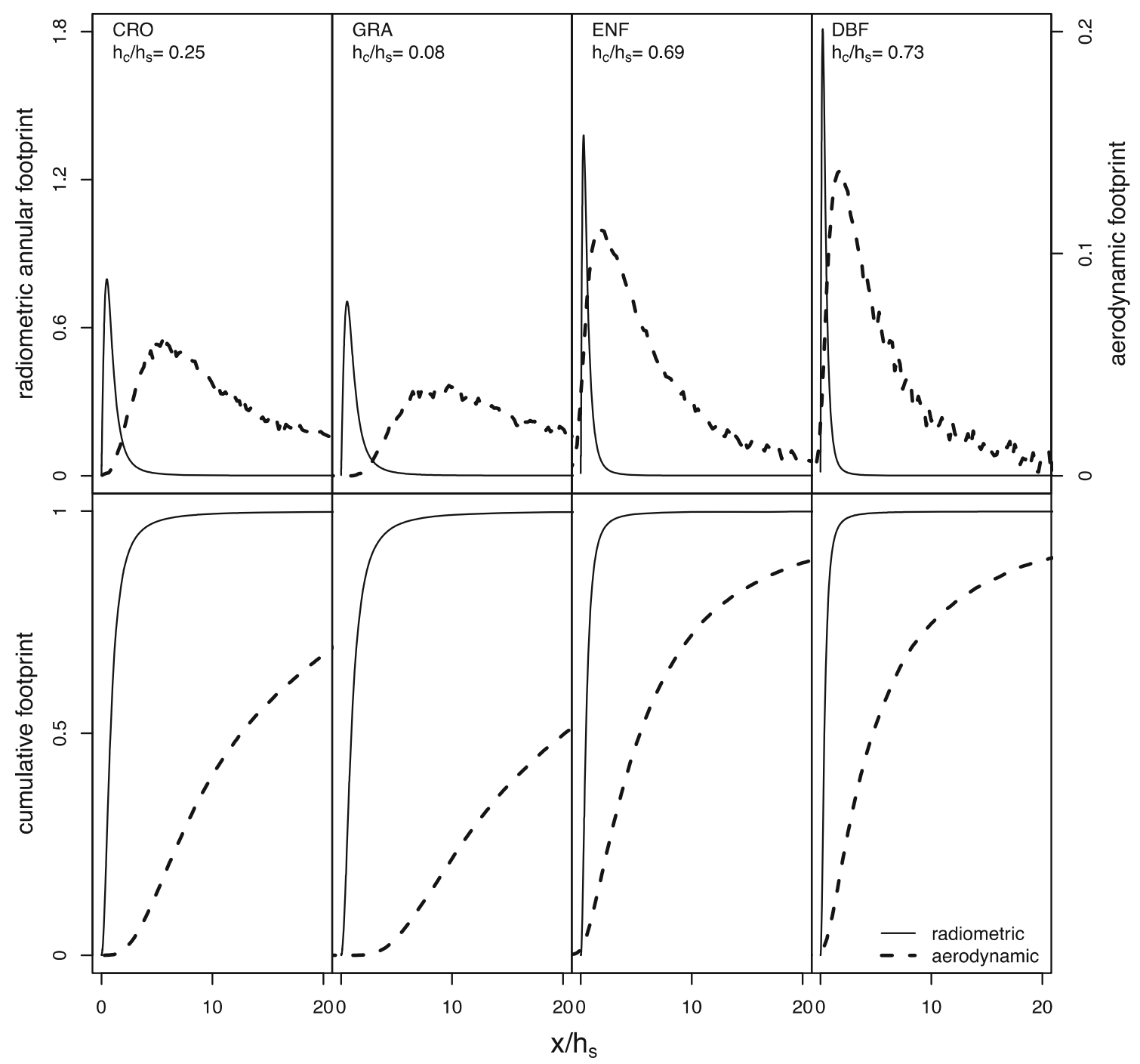

Fig. 4 Radiometric and aerodynamic footprint as functions of the radial distance normalized by canopy height for the model canopies described in Table 1. Probability density functions (top row) and cumulative functions (bottom row) are reported

present analysis shows that the radiometric footprint is systematically smaller and may have a different dependence on LAI changes than the turbulent footprint. For this reason, we may foresee that in the presence of a LAI seasonality, the temporal evolution of the footprint during the growing season can be different for turbulent and radiometric footprints.

\section{Conclusions}

In the last two decades, the network of eddy covariance sites has rapidly expanded to sample the natural variability of landscapes. The spatial heterogeneity of the source intensity at most flux sites raises the issue of matching the source areas of the different measuring systems, given that in several scientific domains, multiple measurements need to be combined. In this context, typical examples are the surface energy balance or the use of optical proximal sensing of canopy reflectance to predict carbon fluxes with different vegetation indexes and metrics (e.g. NDVI, PRI, sun induced fluorescence) (Gamon 2015). Considerable effort has been put so far in formalizing the footprint of turbulent flux measurements. On the contrary, the issue of the radiometric footprint over vegetated canopies has been rarely tackled. Quantifying and characterizing the extent of both footprints is required for the formalized analysis of the two and for a proper comparison that could: (a) help to avoid the problem of footprint mismatch by driving the selection of the experimental site and (b) help to find proper technical solutions to maximize the overlap of the two footprints.

In this study, an analytical formulation of the hemispherical radiometric footprint in presence of vegetation has been proposed. The manuscript focuses on the hemispherical sensor because this geometry is required for several micrometeorological measurements (e.g. short-wave and long-wave upwelling radiation, net radiation, albedo). The same analytical 
Fig. 5 Dependency of the normalized radial distance of the 50th and the 80th percentiles on LAI and canopy to sensor height ratio, for one short canopy (GRA) and one tall canopy (DBF)

Fig. 6 Horizontal distance of the 50th and 80th percentiles at increasing LAI for the aerodynamic and radiometric footprints of the canopy and the soil, for a short canopy (GRA) and a tall canopy (DBF)

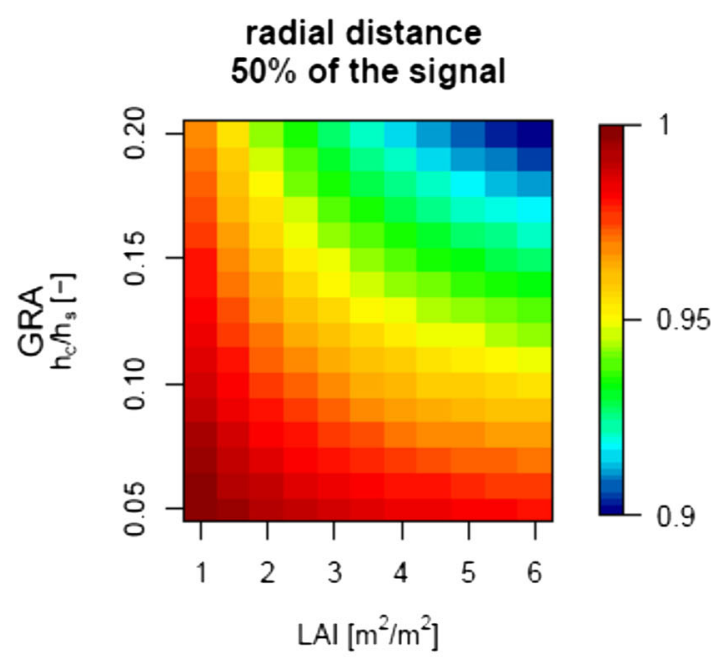

radial distance
$80 \%$ of the signal
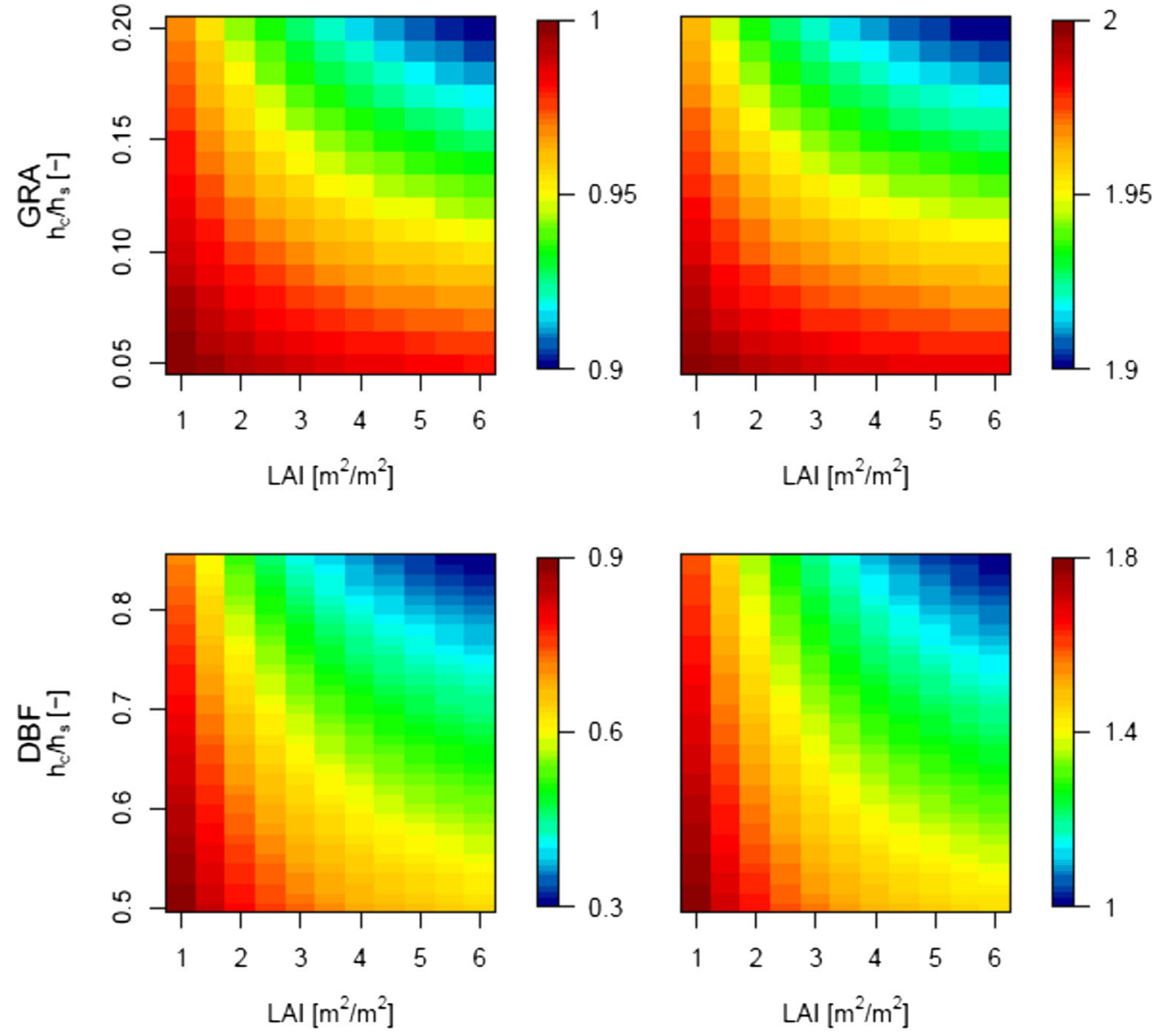

horizontal distance $50^{\text {th }}$ percentile

horizontal distance $80^{\text {th }}$ percentile
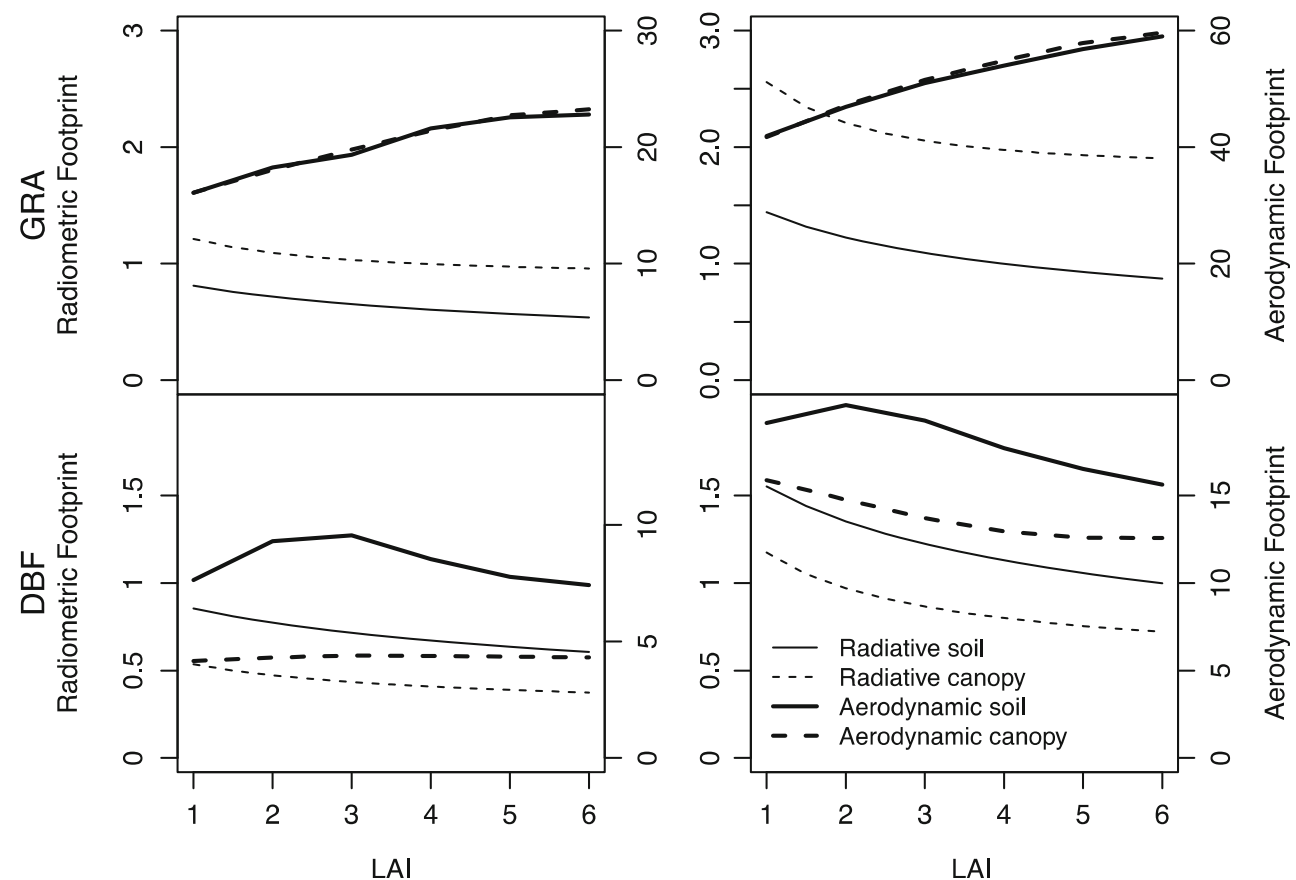
framework could be adopted for narrower fore-optics by changing the integration domain of the equations.

Four model canopies (two short and two tall canopies) were used in the analysis of the dependence of the radiometric footprint source area on the major geometrical features of the canopy. It was observed that if turbulent flux and radiation measurements are performed at the same height, radiometric footprint is always considerably smaller than the aerodynamic one. In fact, close to $100 \%$ of the signal recorded by a radiometer comes from a distance equal to few times the sensor heights, whereas at a distance of 20 sensor heights, the aerodynamic footprint reaches a percentage of the total signal of about $70 \%$ for CRO, $50 \%$ for GRA, and $88 \%$ for ENF and DBF. In order to have a comparable extension of the radiative and aerodynamic footprint, the radiometer should be installed about 15 and 9 times higher than the eddy covariance system for the idealized GRA and CRO and about 6 times higher for ENF and DBF. The size of the radiometric footprint always decreases at increasing LAI, while the aerodynamic footprint increases for GRA and shows a peak at intermediate LAI for DBF. These opposite trends are particularly relevant for deciduous canopies, for which the strong seasonality in LAI ultimately affects the mismatch between the footprint area of aerodynamic and radiometric measurements.

An important finding emerging from this study concerns with the footprint size of soil fluxes versus canopy fluxes. Our analysis shows that for short canopies the radiometric footprint of the soil is systematically smaller than that of the canopy, while for tall canopies the aerodynamic footprint of soil fluxes is typically larger than that of the canopy (Markkanen et al. 2003). The implication of these trends is that the footprint mismatch maximizes for the soil fluxes and is therefore particularly relevant for the processes characterized by large radiative or turbulent fluxes stemming from the ground (e.g. soil respiration, broadband albedo in case of snow-covered forest floors). In conclusion, the formal description of the hemispherical radiometric footprint and its comparison with the aerodynamic footprint provided in this study may help in the design of eddy covariance stations and the integration of flux measurements from multiple sensors and techniques.

Open Access This article is distributed under the terms of the Creative Commons Attribution 4.0 International License (http:// creativecommons.org/licenses/by/4.0/), which permits unrestricted use, distribution, and reproduction in any medium, provided you give appropriate credit to the original author(s) and the source, provide a link to the Creative Commons license, and indicate if changes were made.

\section{References}

Albini F (1981) A phenomenological model for wind speed and shear stress profiles in vegetation cover layers
Baldocchi D (2003) Assessing the eddy covariance technique for evaluating carbon dioxide exchange rates of ecosystems: past, present and future. Glob Chang Biol 9(4):479-492. https://doi.org/10.1046/j. 1365-2486.2003.00629.x

Balzarolo M, Anderson K, Nichol C, Rossini M, Vescovo L, Arriga N, Wohlfahrt G, Calvet J-C, Carrara A, Cerasoli S, Cogliati S, Daumard F, Eklundh L, Elbers JA, Evrendilek F, Handcock RN, Kaduk J, Klumpp K, Longdoz B, Matteucci G, Meroni M, Montagnani L, Ourcival J-M, Sánchez-Cañete EP, Pontailler J-Y, Juszczak R, Scholes B, Martín MP (2011) Ground-based optical measurements at European flux sites: a review of methods, instruments and current controversies. Sensors 11(12):7954-7981. https://doi.org/10.3390/ s110807954

Cescatti A, Marcolla B, Santhana Vannan SK, Pan JY, Roman MO, Yang X, Ciais P, Cook RB, Law BE, Matteucci G, Migliavacca M, Moors E, Richardson AD, Seufert G, Schaaf CB (2012) Intercomparison of MODIS albedo retrievals and in situ measurements across the global FLUXNET network. Remote Sens Environ 121:323-334. https:// doi.org/10.1016/j.rse.2012.02.019

Cescatti A, Niinemets U (2005) Light harvesting: from leaf to landscape. In: smith WK, Chritchley C, Vogelmann T (eds) photosynthetic adaptation. Chloroplast to landscape. Ecological studies, vol 178. Springer Berlin Heidelberg, pp 42-85

Eklundh L, Jin H, Schubert P, Guzinski R, Heliasz M (2011) An optical sensor network for vegetation phenology monitoring and satellite data calibration. Sensors 11(12):7678-7709. https://doi.org/10. 3390/s 110807678

Gamon JA (2015) Reviews and syntheses: optical sampling of the flux tower footprint. Biogeosciences 12(14):4509-4523. https://doi.org/ $10.5194 /$ bg-12-4509-2015

Gamon J, Rahman A, Dungan J, Schildhauer M, Huemmrich K (2006) Spectral network (SpecNet) - what is it and why do we need it? Remote Sens Environ 103(3):227-235. https://doi.org/10.1016/j. rse.2006.04.003

Hsieh CI, Katul G (2009) The Lagrangian stochastic model for estimating footprint and water vapor fluxes over inhomogeneous surfaces. Int $\mathrm{J}$ Biometeorol 53(1):87-100. https://doi.org/10.1007/s00484-0080193-0

Kljun N, Calanca P, Rotach MW, Schmid HP (2015) A simple twodimensional parameterisation for flux footprint prediction (FFP). Geosci Model Dev 8(11):3695-3713. https://doi.org/10.5194/gmd8-3695-2015

Kljun N, Kastner-Klein P, Fedorovich E, Rotach MW (2004) Evaluation of Lagrangian footprint model using data from wind tunnel convective boundary layer. Agric For Meteorol 127(3-4):189-201. https:// doi.org/10.1016/j.agrformet.2004.07.013

Kurbanmuradov O, Rannik Ü, Sabelfeld K, Vesala T (2001) Evaluation of mean concentration and fluxes in turbulent flows by Lagrangian stochastic models. Math Comput Simul 54(6):459-476. https://doi. org/10.1016/S0378-4754(00)00273-1

Law B, Falge E, Gu L, Baldocchi D, Bakwin P, Berbigier P, Davis K, Dolman A, Falk M, Fuentes J, Goldstein A, Granier A, Grelle A, Hollinger D, Janssens I, Jarvis P, Jensen N, Katul G, Mahli Y, Matteucci G, Meyers T, Monson R, Munger W, Oechel W, Olson R, Pilegaard K, Paw UK, Thorgeirsson H, Valentini R, Verma S, Vesala T, Wilson K, Wofsy S (2002) Environmental controls over carbon dioxide and water vapor exchange of terrestrial vegetation. Agric For Meteorol 113:97-120. https://doi.org/10.1016/S01681923(02)00104-1

Marcolla B, Cescatti A (2005) Experimental analysis of flux footprint for varying stability conditions in an alpine meadow. Agric For Meteorol 135(1-4):291-301. https://doi.org/10.1016/j.agrformet.2005.12.007

Marcolla B, Pitacco A, Cescatti A (2003) Canopy architecture and turbulence structure in a coniferous forest. Boundary-Layer Meteorol 108(1):39-59. https://doi.org/10.1023/A:1023027709805 
Markkanen T, Rannik Ü, Marcolla B, Cescatti A, Vesala T (2003) Footprints and fetches for fluxes over forest canopies with varying structure and density. Boundary-Layer Meteorol 106(3):437-459. https://doi.org/10.1023/A:1021261606719

Massman W, Weil J (1999) An analytical one-dimensional second-order closure model of turbulence statistics and the Lagrangian time scale within and above plant canopies of arbitrary. Boundary-Layer Meteorol 91(1):81-107. https://doi.org/10.1023/A:1001810204560

Meroni M, Barducci A, Cogliati S, Castagnoli F, Rossini M, Busetto L, Migliavacca M, Cremonese E, Galvagno M, Colombo R, di Cella UM (2011) The hyperspectral irradiometer, a new instrument for long-term and unattended field spectroscopy measurements. Rev Sci Instrum 82(4):43106. https://doi.org/10.1063/1.3574360

Meroni M, Rossini M, Guanter L, Alonso L, Rascher U, Colombo R, Moreno J (2009) Remote sensing of solar-induced chlorophyll fluorescence: review of methods and applications. Remote Sens Environ 113(10):2037-2051. https://doi.org/10.1016/j.rse.2009.05.003

Nilson T (1971) A theoretical analysis of the frequency of gaps in plant stands. Agric Meteorol 8:25-38. https://doi.org/10.1016/00021571(71)90092-6

Peñuelas J, Garbulsky M, Filella I (2011) Photochemical reflectance index (PRI) and remote sensing of plant CO2 uptake. New Phytol 191(3):596-599. https://doi.org/10.1111/j.1469-8137.2011.03791.x

Rannik Ü, Markkanen T, Raittila J, Hari P, Vesala T (2003) Turbulence statistics inside and over forest: influence on footprint prediction. Boundary-Layer Meteorol 109(2):163-189. https://doi.org/10. 1023/A:1025404923169

Rödenbeck C, Houweling S, Gloor M, Heimann M (2003) $\mathrm{CO}_{2}$ flux history 1982-2001 inferred from atmospheric data using a global inversion of atmospheric transport. Atmos Chem Phys 3(6):19191964. https://doi.org/10.5194/acp-3-1919-2003

Rossini M, Cogliati S, Meroni M, Migliavacca M, Galvagno M, Busetto L, Cremonese E, Julitta T, Siniscalco C, Morra di Cella U, Colombo $\mathrm{R}$ (2012) Remote sensing-based estimation of gross primary production in a subalpine grassland. Biogeosciences 9(7):2565-2584. https://doi.org/10.5194/bg-9-2565-2012
Schmid H (1997) Experimental design for flux measurements: matching scales of observations and fluxes. Agric For Meteorol 87(2-3):179200. https://doi.org/10.1016/S0168-1923(97)00011-7

Schwerdtfeger P (1976) Physical principles of micro-meteorological measurements. Elsevier, Amsterdam

Sims DA, Rahman AF, Cordova VD, El-Masri BZ, Baldocchi DD, Flanagan LB, Goldstein AH, Hollinger DY, Misson L, Monson RK, Oechel WC, Schmid HP, Wofsy SC, Xu L (2006) On the use of MODIS EVI to assess gross primary productivity of north American ecosystems. J Geophys Res 111:G04015. https://doi.org/ 10.1029/2006JG000162

Stoy PC, Mauder M, Foken T, Marcolla B, Boegh E, Ibrom A, Arain MA, Arneth A, Aurela M, Bernhofer C, Cescatti A, Dellwik E, Duce P, Gianelle D, van Gorsel E, Kiely G, Knohl A, Margolis H, McCaughey H, Merbold L, Montagnani L, Papale D, Reichstein M, Saunders M, Serrano-Ortiz P, Sottocornola M, Spano D, Vaccari F, Varlagin A (2013) A data-driven analysis of energy balance closure across FLUXNET research sites: the role of landscape scale heterogeneity. Agric For Meteorol 171-172:137-152. https:// doi.org/10.1016/j.agrformet.2012.11.004

Thomson D (1987) Criteria for the selection of stochastic models of particle trajectories in turbulent flows. J Fluid Mech 180(1):529 556. https://doi.org/10.1017/S0022112087001940

Vesala T, Rannik Ü, Leclerc M, Foken T, Sabelfeld K (2004) Flux and concentration footprints. Agric For Meteorol 127(3-4):111-116. https://doi.org/10.1016/j.agrformet.2004.07.007

Wilson K, Goldstein A, Falge E, Aubinet M, Baldocchi D, Berbigier P, Bernhofer C, Ceulemans R, Dolman H, Field C, Grelle A, Ibrom A, Law B, Kowalski A, Meyers T, Moncrieff J, Monson R, Oechel W, Tenhunen J, Valentini R, Verma S (2002) Energy balance closure at FLUXNET sites. Agric For Meteorol 113(1-4):223-243. https://doi. org/10.1016/S0168-1923(02)00109-0

Wilson N, Shaw R (1977) A higher order closure model for canopy flow. J Appl Meteorol 16(11):1197-1205. https://doi.org/10.1175/15200450(1977)016<1197:AHOCMF>2.0.CO;2 